\title{
Perancangan dan Pengembangan Bed Shower Menggunakan Metode Quality Function Deployment (QFD) Berdasarkan Prinsip Ergonomi
}

\author{
Ayi Fitriani, Hari Purnomo* \\ Jurusan Teknik Industri, Fakultas Teknik, Universitas Islam Indonesia, Jalan Kaliurang Km. 14,5, Daerah Istimewa \\ Yogyakarta 55584, Indonesia
}

\section{ARTICLE INFORMATION}

Article history:

Received: May 21, 2018

Revised: December 21, 2018

Accepted: December 24, 2018

\section{Kata Kunci: \\ Bed shower \\ Desain \\ House of Quality \\ QFD}

\section{Keywords: \\ Bed Shower \\ Design \\ House of Quality \\ QFD}

\footnotetext{
${ }^{*}$ Corresponding Author

Hari Purnomo

E-mail: haripurnomo134@gmail.com
}

\section{A B S T R A K}

Penelitian ini dilakukan untuk merancang bed shower serta mengkaji perancangan dan pengembangan bed shower untuk kebutuhan pasien. Tujuan merancang bed shower dikarenakan kebutuhan alat tersebut untuk mempermudah perawat memandikan pasien yang lumpuh atau tidak dapat menggerakkan anggota tubuhnya. Metode yang digunakan dalam penelitian ini menggunakan pengukuran parameter teknik metode Quality Function Deployment (QFD). Hasil penelitian didapat alat yang dirancang ringan yang menjadi prioritas pertama. Variabel berikutnya yang dipertimbangkan adalah ergonomis, tahan lama, mudah digunakan dan dibersihkan, dan yang terakhir harga terjangkau. Perancangan bed shower lebih memperhatikan prinsip ergonomi dengan memperhatikan material yang digunakan. Bed shower didesain dengan tiga dimensi menggunakan software Solid Work dengan penerjemahan konsep yang diinginkan konsumen diwujudkan dengan diberikan roda pada trolley dan alas mandi yang mudah kering serta mudah dilipat dan dibawa. Sedangkan ukuran alat dengan panjang $216 \mathrm{~cm}$, lebar 60 $\mathrm{cm}$, tinggi trolley $107 \mathrm{~cm}$, lebar trolley $29 \mathrm{~cm}$, display alat yang mudah dan praktis, mudah dibersihkan memungkinkan alat untuk dirangkai lepas, memiliki daya tahan yang awet dengan perkiraan lebih dari 5 tahun masa ekonomis, memiliki harga yang murah berada pada kisaran Rp. 5.000.000,dengan pembuatan dari material pilihan dan memaksimalkan fungsi 1 pompa.

\section{A B S T R A C T}

This research was conducted to design a bed shower and study the design and development of a bed shower for patient needs. The purpose of creating a bed shower is because of the lack for these tools to make it easier for nurses to bathe patients who are paralyzed or unable to move their limbs. The method used in this study uses the measurement parameters of the Quality Function Deployment (QFD) method. The results of the study obtained lightly designed tools that were the priority. The next variable that is considered is ergonomic, durable, comfortable to use and clean, and finally, the price is affordable. The design of the bed shower pays more attention to the principle of ergonomics by paying attention to the material used. Bed shower designed with three dimensions using Solid Work software with the translation of the concept that consumers want is realized by providing trolley wheels and bath pads that are easily dry and easily folded and carried. While the size of the tool with a length of $216 \mathrm{~cm}$, width of $60 \mathrm{~cm}$, trolley height of $107 \mathrm{~cm}$, width of the trolley of $29 \mathrm{~cm}$, display tools that are easy and practical, easy to clean allow tools to be separated, have durable durability with an estimate of more than 5 years, having a cheap price is around Rp. 5,000,000, - by making selected materials and maximizing the function of one pump. 


\section{PENDAHULUAN}

Perkembangan teknologi memicu perkembangan konsep produk baru dan berbagai inovasi. Orientasi pengembangan produk telah berubah dari orientasi dalam bidang produksi menjadi orientasi bidang pemasaran, dan berorientasi kepada pelanggan [1]. Perancangan dan pengembangan produk menjadi bagian dari perubahan abstrak dalam dunia usaha. Era globalisasi dewasa ini kreasi dan inovasi dituntut untuk selalu berkembang guna mengikuti perkembangan teknologi [2]. Perkembangan teknologi dari masa ke masa mempunyai dampak pada bidang kehidupan manusia, termasuk bidang kesehatan. Penelitian dengan memanfaatkan teknologi menghasilkan temuan baru untuk perkembangan ilmu kesehatan, termasuk bagi pasien disabilitas.

Berdasarkan data Departemen Kesehatan RI, prevalensi stroke usia $\geq 15$ tahun di Indonesia sebesar $7 \%$ dan gejala sebesar $12,1 \%$. Prevalensi stroke tertinggi di Sulawesi Utara $(10,8 \%)$, diikuti DI Yogyakarta (10,3\%), Bangka Belitung dan DKI Jakarta masing-masing 9,7\%. Prevalensi Stroke berdasarkan gejala tertinggi terdapat di Sulawesi Selatan (17,9\%), DI Yogyakarta $(16,9 \%)$, Sulawesi Tengah (16,6\%), diikuti Jawa Timur (16\%). Sedangkan data disabilitas dengan kesulitan membersihkan diri sebesar $6 \%$, dimana $1,8 \%$ dengan tingkat sedang hingga sangat berat yang tidak mampu membersihkan diri [3]

Seseorang yang mengalami lumpuh, semua aktivitas dilakukan di atas tempat tidur dan bergantung pada orang lain, baik aktivitas yang berhubungan dengan buang air besar/kecil, mandi, makan/minum, berpakaian, merias diri dan lain-lain [4]. Masalah yang sering timbul pada penderita lumpuh adalah kurang terjaganya kebersihan karena keterbatasan penderita dan keluarga. Salah satu penyakit yang timbul akibat kebersihan pada orang lumpuh adalah gangguan eksema yang apabila tidak diobati dengan benar akan menimbulkan masalah serius [5]. Selain itu proses pengangkatan pasien ke kamar mandi untuk dibersihkan ataupun dimandikan akan menimbulkan cedera akibat pengangkatan beban berat yang terlalu sering.
Solusi medis terkini untuk memudahkan masalah hygiene khususnya mandi dan membersihkan tubuh untuk orang yang mempunyai keterbatasan adalah bed shower [6]. Prinsip kerja alat ini sederhana dimana pasien tidak perlu meninggalkan tempat tidur untuk mandi. Akan tetapi alat tersebut masih mahal untuk kebutuhan perawatan di rumah dan hanya dimiliki oleh rumah sakit dengan skala menengah ke atas. Berdasarkan situs penjualan alat medis Medical Eshop [7], harga bed shower atau shower trolley berkisar $\$ 4,469.00$ atau setara $\mathrm{Rp}$. 62.566.000. Hal tersebut menjadi masalah bagi masyarakat Indonesia yang sebagian besar berada pada taraf hidup menengah ke bawah [8] sehingga berat membeli alat bed shower. Penelitian yang terkait dengan QFD telah banyak dilakukan, seperti penelitian yang menerjemahkan evaluasi teknis dari hasil QFD menjadi hasil yang berorientasi kepada konsumen dengan mempertimbangkan berbagai aspek [9]. QFD dapat digunakan untuk mengatasi perbedaan antara beragam kebutuhan konsumen [10] dan perancangan ulang suatu produk untuk menghemat waktu dan biaya produksi [11]. Berdasarkan permasalahan di atas, penelitian ini dilakukan untuk mengembangkan desain bed shower berdasarkan suara konsumen dengan menggunakan metode QFD. Tujuan perancangan dan pengembangan produk ini untuk merancang bed shower dengan design yang ergonomis dan biaya rendah tanpa mengurangi nilai fungsi alat tersebut.

\section{METODE PENELITIAN}

\section{Objek dan subyek penelitian}

Fokus kajian penelitian adalah perancangan bed shower yang ekonomis menggunakan metode QFD dengan harga yang tidak terlalu mahal. Objek penelitian ini adalah bed shower untuk membersihkan atau memandikan orang yang mengalami cacat fisik ataupun kelumpuhan. Subjek penelitian yang digunakan sebagai responden adalah orang yang pernah memandikan orang sakit yang tidak mampu untuk membersihkan diri. Kriteria inklusi responden antara lain: (1) dalam kondisi sehat; (2) telah merawat pasien minimal satu tahun; (3) usia antara 20-45 tahun. Sedangkan responden lainnya adalah pasien yang pernah dimandikan atau dirawat dengan kriteria inklusi antara lain: (1) dalam kondisi sadar dan mampu diajak berkomunikasi; (2) usia pasien maksimal 60 tahun; (3) warga negara Indonesia. 
Jumlah Sampel

Kebutuhan konsumen dilakukan melalui penyebaran kuesioner tertutup terhadap responden menggunakan non-probability sampling. Rumus untuk menentukan jumlah sampel menggunakan konsep yang dikembangkan oleh Walpole [12] untuk jumlah populasi yang belum diketahui.

$n=\frac{A^{2} \times B(1-B)}{d^{2}}$

Keterangan :

$n \quad:$ Jumlah sampel

A : Tingkat kepercayaan

B $\quad$ : Maksimal estimasi $=0,5$

$d \quad$ : Margin of error.

Berdasarkan perhitungan di atas dengan asumsi Dengan tingkat keyakinan $95 \%$ dan margin of error $10 \%$ maka jumlah minimal responden sebesar 97 orang. Dalam penelitian ini jumlah responden yang digunakan sebanyak 100 orang.

\section{Perancangan Alat}

Pada tahap perancangan menggunakan metode QFD. Metode ini merupakan cara mengembangkan kualitas jasa atau barang berdasarkan kebutuhan konsumen dengan menghubungkan ketentuan teknis [13]. Tahapan dalam penyusunan penelitian sebagai berikut:

a. Identifikasi Kebutuhan Konsumen

Menentukan kebutuhan konsumen mengenai produk yang akan dikembangkan, meliputi tahapan berikut: (1) Identifikasi produk yang akan dikaji. Penentuan produk menjadi langkah pertama dalam tahap identifikasi kebutuhan konsumen dan juga menjadi batasan sekaligus tujuan penelitian; (2) Menentukan costumer needs. Kebutuhan konsumen didapatkan dari kuesioner yang dibagikan. Isi dari kebutuhan konsumen adalah harapan konsumen mengenai produk yang dirancang dan digunakan sebagai acuan untuk pengembangan produk; (3) Menentukan importance rating. Penentuan tingkat kepentingan konsumen digunakan untuk mengetahui sejauh mana konsumen memberikan penilaian atau harapan dari kebutuhan konsumen.

b. Uji Validitas dan Reliabilitas

Hasil rekapitulasi kuesioner tertutup mengenai derajat kepentingan terhadap atribut produk bed shower terlebih dahulu diuji validitas dan reliabilitas sebelum dilakukan pengolahan lebih lanjut. Uji validitas dan reliabilitas digunakan untuk mengetahui apakah data yang didapatkan valid dan reliable sehingga penelitian dapat dilanjutkan.

c. Pembuatan Matriks House of Quality (HOQ) Matriks $\mathrm{HOQ}$ didasarkan pada hasil perolehan kuesioner kebutuhan konsumen dan wawancara dengan ahli. Tahapan pembuatan HOQ meliputi: (1) Menentukan technical requirement. Proses pada tahap ini adalah merubah bahasa konsumen menjadi bahasa teknis perusahaan. Penerjemahan suara kebutuhan konsumen menjadi karakterisistikkarakteristik dari produk untuk memenuhi harapan dan kebutuhan konsumen [14]; (2) Menentukan relationship. Tahap ini berisi penentuan nilai hubungan antara karakteristik teknis perusahaan dengan tingkat kebutuhan konsumen. Keluaran dari tahap ini adalah mengetahui seberapa kuat dan berpengaruh sebuah karakterisktik produk terhadap kepuasan memenuhi kebutuhan konsumen [15]; (3) Menentukan target. Target dalam hal ini adalah sasaran untuk dicapai, yang dirumuskan dan ditetapkan berdasarkan kebutuhan konsumen dan karakterisktik teknis. Target merupakan penjabaran dan perincian dari karakteristik teknik itu sendiri; (4) Membuat matriks korelasi. Dalam tahap ini adalah proses penilaian hubungan antar karakteristik teknik yang sudah ditetapkan yaitu apakah saling bertolak belakang atau tidak [15]; (5) Menentukan bobot kolom. Bobot kolom didapatkan dari hubungan-hubungan korelasi antara costumer needs dan technical requirement yang ditentukan dari jenis hubungan yang berlangsung; (6) Menentukan sales point. Pada tahap ini merupakan penilaian dari nilai jual dari masing-masing variabel produk [16].

\section{Desain rancangan produk 3D}

Desain rancangan alat dibuat dengan software Solid Work. Proses desain produk menyesuaikan dengan target pencapaian $\mathrm{HOQ}$, selanjutnya dilakukan analisis untuk kesesuaian dengan kebutuhan konsumen. Hasil rancangan dilakukan evaluasi yang digunakan sebagai masukan dan saran serta keluhan sebagai bahan untuk melakukan perbaikan yang sesuai dengan kebutuhan dan keinginan konsumen.

\section{HASIL DAN PEMBAHASAN}

\section{Karakteristik Responden}

Identifikasi kebutuhan konsumen ditunjukkan pada Tabel 1. Identifikasi konsumen dapat dijelaskan bahwa atribut yang memiliki nilai 
tertinggi yaitu harga, mudah digunakan, alat ringan, ergonomis, dapat dipindahkan, dan tahan lama.

Tabel 1. Rekapitulasi Kuesioner Kebutuhan Konsumen

\begin{tabular}{lc}
\hline \multicolumn{1}{c}{ Atribut } & Jumlah \\
\hline Harga & 75 \\
Penggunaan & 66 \\
Bobot Alat & 64 \\
Nyaman dan Aman & 56 \\
Mobile & 49 \\
Ketahanan & 43 \\
Praktis & 33 \\
Waterproof & 22 \\
Desain menarik & 19 \\
Display mudah & 18 \\
Multifungsi & 17 \\
Pengatur suhu Air & 14 \\
Ramah lingkungan & 8 \\
Rapih dalam & 7 \\
penggunaannya & \\
Sparepart mudah dicari & 2 \\
Hemat energi & 2 \\
Total & 495
\end{tabular}

Hasil uji validitas dari atribut terpilih dapat dijelaskan bahwa semua data valid yang ditunjukkan pada Tabel 2. Berdasarkan uji validitas diperoleh nilai $r$ hitung $>r$ tabel. Dengan demikian dapat disimpulkan bahwa instrumen dari daftar keinginan customer dinyatakan valid. Sedangkan hasil uji reliabilitas menunjukkan nilai Cronbach's Alpha 0,623 untuk keinginan customer yang menunjukkan hasil bisa diterima.
Tabel 2. Uji Validitas

\begin{tabular}{|c|c|c|c|}
\hline Variabel & $\mathrm{R}_{\text {Tabel }}$ & R Hitung & Uji Validitas \\
\hline Harga & \multirow{6}{*}{0,195} & 0,329 & Valid \\
\hline Penggunaan & & 0,448 & Valid \\
\hline Bobot Alat & & 0,355 & Valid \\
\hline $\begin{array}{l}\text { Nyaman dan } \\
\text { Aman }\end{array}$ & & 0,314 & Valid \\
\hline Mobile & & 0.694 & Valid \\
\hline Ketahanan & & 0,714 & Valid \\
\hline
\end{tabular}

Tabel 3. Tingkat Kepentingan Konsumen

\begin{tabular}{lcccccc}
\hline \multirow{1}{*}{ Kriteria } & \multicolumn{4}{c}{ Skala Point } & \multicolumn{2}{c}{ Tingkat } \\
& 1 & 2 & 3 & 4 & 5 & Kepentingan \\
\hline Harga & 0 & 24 & 26 & 24 & 26 & 3 \\
Penggunaan & 2 & 11 & 29 & 31 & 27 & 4 \\
Bobot Alat & 1 & 25 & 33 & 21 & 20 & 3 \\
Nyaman dan & 2 & 10 & 36 & 33 & 19 & 3 \\
Aman & 2 & 17 & 38 & 19 & 25 & 3 \\
Mobile & 0 & 18 & 32 & 27 & 23 & 3 \\
Ketahanan & 0 &
\end{tabular}

Tingkat kepentingan atribut (importance to customer) adalah nilai yang menunjukkan seberapa penting atribut dalam menentukan kualitas produk, juga untuk mengetahui sejauh mana konsumen memberikan penilaian atau harapan dari kebutuhan konsumen [13]. Pada Tabel 3 menunjukkan bahwa tingkat kepentingan tertinggi adalah mudah digunakan dan dibersihkan. Tabel 4 merupakan karakteristik dan target untuk memenuhi kebutuhan konsumen

Tabel 4. Karakteristik Teknis dan Target untuk Memenuhi Keinginan Konsumen

\begin{tabular}{|c|c|c|}
\hline Variabel & Karakteristik teknis & Target \\
\hline Harga & Harga terjangkau & Harga alat $\pm \operatorname{Rp} 5.000 .000,-$ \\
\hline Penggunaan & $\begin{array}{l}\text { Mudah digunakan dan } \\
\text { dibersihkan }\end{array}$ & $\begin{array}{l}\text { Display alat mudah, } \\
\text { Alat praktis digunakan, } \\
\text { Komponen alat mudah dirangkai lepas dan mudah } \\
\text { dibersihkan. }\end{array}$ \\
\hline Bobot alat & Alat ringan & $\begin{array}{l}\text { Bahan yang digunakan ringan dengan dibantu roda } \\
\text { yang memudahkan dalam perpindahan dan } \\
\text { pengangkatan }\end{array}$ \\
\hline Nyaman dan aman & $\begin{array}{l}\text { Ergonomis (Rancangan } \\
\text { sesuai antropometri) }\end{array}$ & $\begin{array}{l}\text { Ukuran Bath Tub untuk pasien dan troli untuk } \\
\text { pengguna sesuai ukuran dimensi tubuh manusia }\end{array}$ \\
\hline Mobile & Alat dapat dipindahkan & Terdapat roda pada bagian troli alat penampung air \\
\hline Ketahanan & Tahan lama & Komponen yang digunakan tahan lama/awet \\
\hline
\end{tabular}


Bagian terpenting QFD adalah membangun House of Quality (HOQ), seperti ditunjukkan pada Gambar 1. Berdasarkan matriks $\mathrm{HOQ}$ didapat bobot kolom masing-masing sebesar $63,57,43$, 57, 63, dan 57. Bobot kolom tertinggi adalah alat yang dirancang ringan dan perancangan alat yang ergonomis. Variabel berikutnya yang dipertimbangkan adalah komponen yang digunakan tahan lama, mudah digunakan dan dibersihkan, dan yang terakhir harga terjangkau.

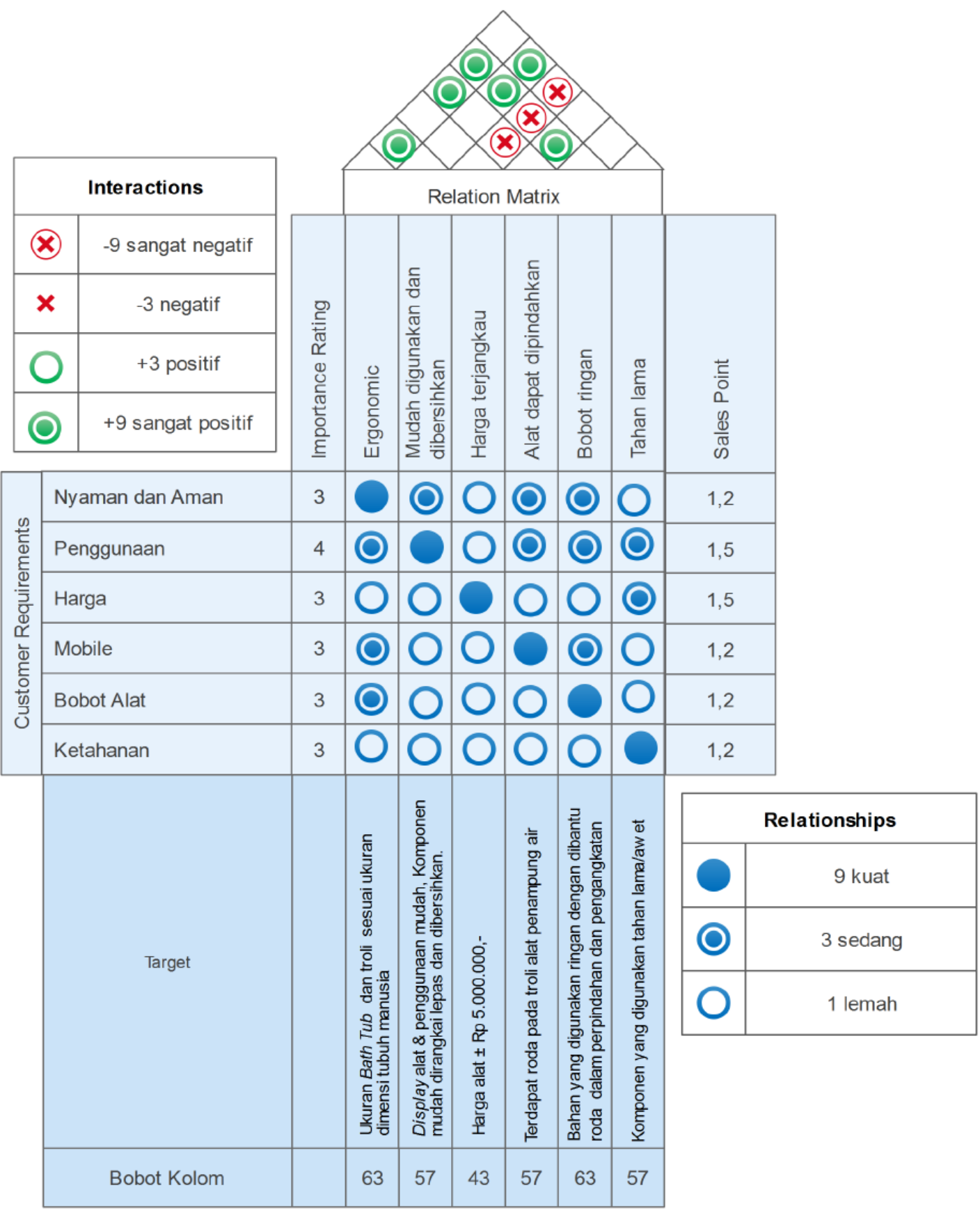

Gambar 1. Matriks HOQ

Proses perancangan dari aspek ergonomi, menggunakan data persentil pengguna yang berjumlah 100 orang dengan nilai persentil yang digunakan. Tabel 5 menjelaskan dimensi tubuh yang dipertimbangkan dalam rancangan dan nilai persentil yang digunakan. 
Tabel 5. Daftar nilai persentil variabel pengukuran

\begin{tabular}{llllll}
\hline \multirow{2}{*}{ Variabel } & \multicolumn{3}{c}{ Percentiles } & \multirow{2}{*}{ Allowance } & Ukuran yang digunakan \\
& 5 & 50 & 95 & & \\
\hline Lebar Bahu (LB) & 39,12 & 43,06 & 49,95 & $9,99 \sim 10$ & $59,95 \sim 60 \mathrm{~cm}$ \\
Tinggi Badan Tegak (TBT) & 162,05 & 171,50 & 179,95 & $35,99 \sim 36$ & $215,95 \sim 216 \mathrm{~cm}$ \\
Tinggi Siku Berdiri (TSB) & 102,00 & 107,00 & 114,00 & - & $107,00 \mathrm{~cm}$ \\
\hline
\end{tabular}

Rancangan alat untuk aspek ergonomis menggunakan ukuran dimensi tubuh pengguna dengan ketentuan antropometri sebagai berikut:

a. Lebar alas untuk memandikan pasien menggunakan dimensi tubuh LB dengan menggunakan persentil ke-95 dengan nilai 49,95. Penggunaan persentil ke-95 ditujukan agar ukuran lebar alas bed shower sesuai dengan ukuran orang terbesar dan bisa digunakan oleh orang yang berukuran besar ataupun kecil [17], [18]. Nilai ini ditambah dengan $20 \%$ sebagai kelonggaran karena dalam kategori dinamis. Nilai kelonggaran \pm $10 \mathrm{~cm}$ maka lebar bed shower untuk memandikan sebesar $\pm 60 \mathrm{~cm}$.

b. Panjang alas untuk memandikan pasien menggunakan dimensi tubuh TBT dengan menggunakan persentil ke-95 dengan nilai 179,95. Nilai tersebut ditambahkan dengan kelonggaran $20 \%$ sehingga ukuran panjang alas menjadi \pm 216 .

c. Tinggi handle troli penampungan air menggunakan dimensi tubuh TSB dengan menggunkan persentil ke-50 dengan nilai 107 $\mathrm{cm}$. Penggunaan persentil ke-50 dimaksudkan agar ukuran untuk tinggi troli sesuai dengan ukuran rata-rata orang pada umumnya [19].

Setelah melakukan perancangan produk bed shower dengan menggunakan metode Quality Function Deployment (QFD) kemudian desain alat dituangkan melalui gambar tiga dimensi menggunakan software Solid work 2013. Ukuran alat yang termasuk pengukuran dimensi antropometri adalah lebar alas bed shower $60 \mathrm{~cm}$ (A), panjang alas bed shower $216 \mathrm{~cm}$ (B), dan tinggi handle trolley $107 \mathrm{~cm}$ (E). Sedangkan ukuran yang tidak termasuk dalam pengukuran antropometri disesuaikan dengan kebutuhan antara lain: tinggi alas bed shower $20 \mathrm{~cm}(\mathrm{C})$, lebar handle trolley $29 \mathrm{~cm}$ (D), lebar box bawah trolley $32 \mathrm{~cm}(\mathrm{~F})$, panjang box trolley $85 \mathrm{~cm}(\mathrm{G})$, lebar penutup atas trolley $14 \mathrm{~cm}(\mathrm{H})$, lebar penutup samping trolley $30 \mathrm{~cm}(\mathrm{I})$, dan tinggi penutup samping trolley $85 \mathrm{~cm}(\mathrm{~J})$.

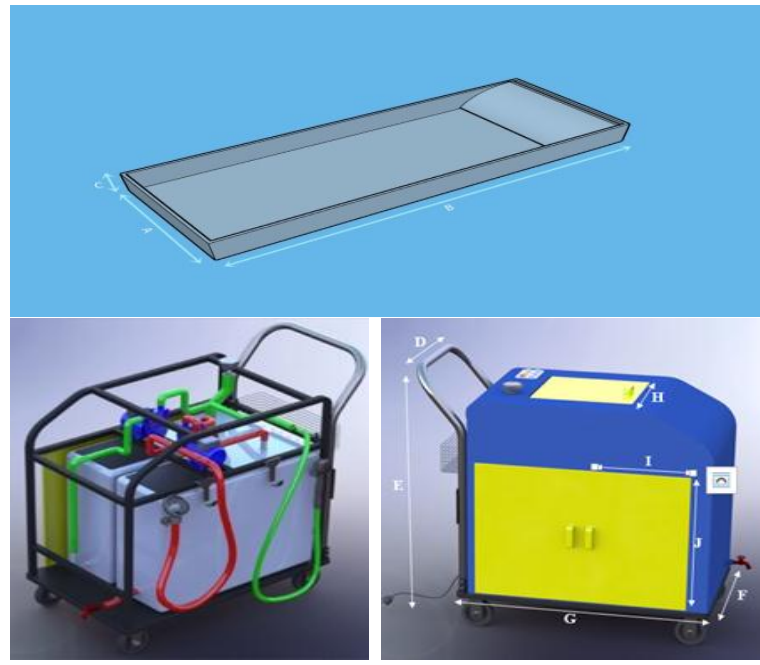

Gambar 2. Lebar alas dan panjang alas bed shower serta komponen trolley

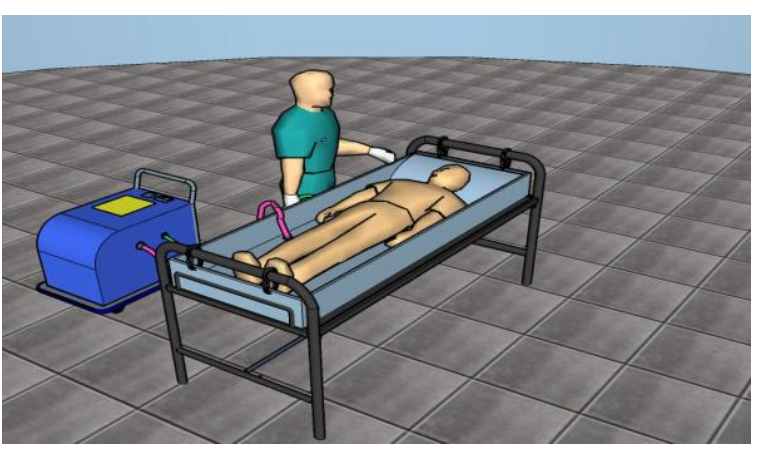

Gambar 3. Visualisasi penggunaan alat \#1

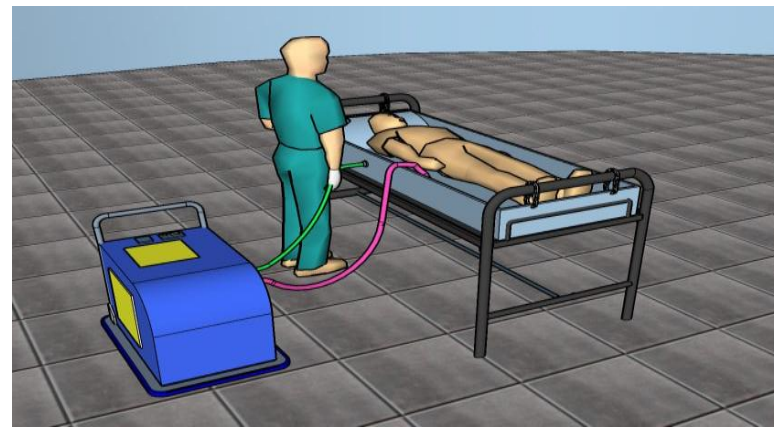

Gambar 4. Visualisasi penggunaan alat \#2 
Hasil penelitian dapat menjelaskan bahwa kebutuhan konsumen yang nyaman dan aman merupakan keniscayaan dalam proses perancangan dan pengembangan produk yang berhubungan dengan manusia. Aspek kenyamanan dan keamanan diperlukan desain yang ergonomis sesuai dengan kebutuhan pengguna [20]. Dalam memenuhi kriteria teknis yang diusulkan maka target dari variabel aman dan nyaman adalah ukuran bath tub untuk memandikan pasien dan ukuran troli penampung air sesuai dengan ukuran dimensi tubuh manusia. Pernyataan tersebut didukung dalam penelitian yang dilakukan oleh Taifa dan Desai [19] yang mengemukakan bahwa ilmu antropometri penting guna menunjang kenyamanan dan keamanan dalam sebuah desain suatu alat. Aspek penggunaan diperoleh karakteristik teknis mudah digunakan dan dibersihkan. Untuk menterjemahkan karakteristik teknis tersebut maka ditargetkan bahwa display alat mudah, praktis dalam penggunaan, dan komponen alat mudah dilepas sehingga mudah untuk dibersihkan [21].

Penentuan harga sangat menentukan posisi produk dipasaran [22]. Bed shower ditargetkan dipasarkan dengan harga \pm Rp. 5.000.000,- yang dapat dijangkau oleh masyarakat umum. Sedangkan penambahan roda sebagai alat perpindahan dan untuk memudahkan dalam penggunaan. Roda juga harus mampu menanggung beban berat troli yang terisi penuh. Spesifikasi roda yang diusulkan dalam troli penampung air alat bed shower adalah roda Polyurethane dengan ukuran 4" (100 x 32 mm)(Drat: 5/8") kapasitas yang dapat ditahan sebesar $135 \mathrm{~kg}$. Begitu juga dengan komponen alas memandikan pasien dirancang dapat dilipat dan dipindahkan sesuai posisi pasien. Bobot alat diusahakan ringan dengan menggunakan bahan yang ringan dengan dibantu roda untuk memudahkan dalam perpindahan dan pengangkatan. Keuntungan lain, mengurangi pengangkatan beban dari alat yang terlalu berat. Hal ini dapat mengurangi musculoskeletal disorders atau cedera akibat mengangkat beban berat yang terlalu sering [23]. Aspek ketahanan bertujuan agar bed shower yang digunakan dapat bertahan lama, sehingga tidak perlu dilakukan penggantian komponen terutama komponen penyusun utama [24]. Agar alat memiliki ketahanan digunakan komponen utama berbahan kain Gore-Tex dan troli yang berbahan dasar Stainless-Steel yang mampu bertahan selama \pm 4 tahun [2]

\section{KESIMPULAN}

Berdasarkan hasil pengolahan, analisis data, dan rumusan penelitian dapat diambil beberapa kesimpulan bahwa kebutuhan konsumen terhadap produk bed shower terdapatl enam (6) atribut karakteristik produk dengan nilai tertinggi. Atribut tersebut adalah nyaman dan aman, penggunaan, harga, mobile, bobot Alat, dan ketahanan dengan masing-masing karakteristik teknis yaitu ergonomis, mudah digunakan dan dibersihkan, harga terjangkau, alat dapat dipindahkan, ringan, dan alat tahan lama. Konsep bed shower dengan biaya rendah dan harga dapat terjangkau masyarakat. Material yang digunakan adalah stainless steel untuk sebagian besar rangka alat serta menggunakan pemakaian kain Gore-Tex untuk alas mandi. Alat didesain sederhana agar biaya produksi murah dengan memaksimalkan satu pompa.

Hasil bed shower yang dirancang antara lain: (a) mudah dipindahkan dan ringan, dengan dipasang roda pada trolley dengan alas mandi yang mudah kering serta mudah dilipat dan dibawa; (b) Ukuran alat sesuai dengan antropometri dengan panjang $216 \mathrm{~cm}$, lebar $60 \mathrm{~cm}$ dan tinggi $107 \mathrm{~cm}$ serta lebar handle $29 \mathrm{~cm}$; (c) Mudah dan praktis digunakan; (d) Mudah dibersihkan, yang diwujudkan dalam desain yang memungkinkan alat untuk dirangkai lepas seperti pada bagian penampungnya; (e) Memiliki daya tahan dengan perkiraan lebih dari 5 tahun umur ekonomis; (f) Memiliki harga yang murah dengan kisaran harga 5 juta rupiah.

\section{DAFTAR PUSTAKA}

[1] K.-A. Hsiao and L.-L. Chen, "Fundamental dimensions of affective responses to product shapes," Int. J. Ind. Ergon., vol. 36, no. 6, pp. 553-564, 2006.

[2] T. Poulain, J. Mendez, G. Henaff, and L. De Baglion, "Characterization of damage during low cycle fatigue of a $304 \mathrm{~L}$ austenitic stainless steel as a function of environment (air, PWR environment) and surface finish (polished, ground)," Procedia Eng., vol. 160, pp. 123-130, 2016.

[3] Kementerian Kesehatan Republic of Indonesia, Profil kesehatan Indonesia tahun 2013. Jakarta: Kementerian Kesehatan RI, 2014.

[4] A. Stephan-Carlier, J. Facione, E. Speyer, E. Rumilly, and J. Paysant, "Quality of life and satisfaction after multilevel surgery in cerebral palsy: Confronting the experience of children and their parents," 
Ann. Phys. Rehabil. Med., vol. 57, no. 910, pp. 640-652, 2014.

[5] C. Cosseau et al., "Proteobacteria from the human skin microbiota: species-level diversity and hypotheses," One Heal., vol. 2, pp. 33-41, 2016.

[6] N. Nevala and L. Tamminen-Peter, "Ergonomics and usability of an electrically adjustable shower trolley," Int. J. Ind. Ergon., vol. 34, no. 2, pp. 131-138, 2004.

[7] Medical Eshop, "ArjoHuntleigh Concerto Shower Trolley- Basic (online)," 2017. [Online]. Available: https://www.medicaleshop.com/arjohuntlei gh-carevo-shower-trolley.html.

[8] Badan Pusat Statistik, Pendapatan Nasional Indonesia 2012-2016. Jakarta: Badan Pusat Statistik, 2017.

[9] J. Servert, A. Labanda, E. Fuentealba, M. Cortes, and R. Pérez, "Quality Function Deployment analysis for the selection of four utility-scale solar energy projects in northern Chile," Energy Procedia, vol. 49, pp. 1896-1905, 2014.

[10] D. Y. Irawati, M. L. Singgih, and B. Syarudin, "Integrasi Quality Function Deployment (QFD) dan Conjoint Analysis untuk Mengetahui Preferensi Konsumen," J. Optimasi Sist. Ind., vol. 13, no. 2, pp. 618-640, 2016.

[11] F. Ardani, R. Ginting, and A. Ishak, "Perancangan Desain Produk Spring Bed Dengan Menggunakan Metode Quality Function Deployment," J. Tek. Ind. USU, vol. 5, no. 1, 2014.

[12] R. E. Walpole and C. B. Allendoerfer, Introduction to statistics, vol. 2. New York, 1974.

[13] Y. Akao, B. King, and G. H. Mazur, Quality function deployment: integrating customer requirements into product design. Cambridge: Productivity press, 1990.

[14] L. R. Guinta, The QFD book: The team approach to solving problems and satisfying customers through quality function deployment. New York: Amacom, 1993.

[15] R. G. Day, Quality function deployment: Linking a company with its customers. Milwaukee: ASQC Quality Press, 1993.

[16] J. B. Revelle, J. W. Moran, and C. A. Cox, The QFD handbook. NewYork: John Wiley \& Sons, 1998.

[17] A. Altaboli, M. Belkhear, A. Bosenina, and N. Elfsei, "Anthropometric evaluation of the design of the classroom desk for the fourth and fifth grades of Benghazi primary schools," Procedia Manuf., vol. 3, pp. 5655-5662, 2015.

[18] R. Alojado, B. Custodio, K. M. Lasala, and $P$. L. Marigomen, "Designing an ergonomic chair for pedicurists and manicurists in Quezon City, Philippines," Procedia Manuf., vol. 3, pp. 1812-1816, 2015.

[19] I. W. Taifa and D. A. Desai, "Anthropometric measurements for ergonomic design of students' furniture in India," Eng. Sci. Technol. an Int. J., vol. 20, no. 1, pp. 232-239, 2017.

[20] D. O. N. Diban and L. A. Gontijo, "The complexity of ergonomic in product design requirements," Procedia Manuf., vol. 3, pp. 6169-6174, 2015.

[21] A. Chen and L. Zhou, "The Improved Design of Sub-assembling Tray for an Engine," Procedia Eng., vol. 174, pp. 512-517, 2017.

[22] Ö. Erkarslan and H. Yılmaz, "Optimization of product design through quality function deployment and analytical hierarchy process: case study of a ceramic washbasin," 2011.

[23] A. M. Basahel, "Investigation of workrelated Musculoskeletal Disorders (MSDs) in warehouse workers in Saudi Arabia," Procedia Manuf., vol. 3, pp. 4643-4649, 2015.

[24] S. Cruchley, M. Twite, A. Tweddle, G. Wagner, A. Wisbey, and R. Lee, "A novel method for uniaxial HCF testing of austenitic stainless steels," Procedia Eng., vol. 160, pp. 285-291, 2016. 